OPEN ACCESS

Edited by:

Christine Ann Denny,

Columbia University Irving Medical

Center, United States

Reviewed by:

Hélène Marie,

Centre National de la Recherche

Scientifique (CNRS), France

Xiao-Bing Gao,

School of Medicine, Yale University,

United States

*Correspondence:

Salvatore Fusco

salvatore.fusco@unicatt.it

${ }^{\dagger}$ These authors have contributed equally to this work

Specialty section:

This article was submitted to

Molecular Medicine,

a section of the journal

Frontiers in Cell and Developmental

Biology

Received: 09 April 2020

Accepted: 31 July 2020

Published: 19 August 2020

Citation:

Ripoli C, Spinelli M, Natale F, Fusco $S$ and Grassi C (2020) Glucose

Overload Inhibits Glutamatergic Synaptic Transmission: A Novel Role

for CREB-Mediated Regulation

of Synaptotagmins 2 and 4.

Front. Cell Dev. Biol. 8:810.

doi: 10.3389/fcell.2020.00810

\section{Glucose Overload Inhibits Glutamatergic Synaptic Transmission: A Novel Role for CREB-Mediated Regulation of Synaptotagmins 2 and 4}

\author{
Cristian Ripoli1,2t, Matteo Spinelli1†, Francesca Natale ${ }^{1}$, Salvatore Fusco ${ }^{1,2 *}$ and \\ Claudio Grassi ${ }^{1,2}$
}

${ }^{1}$ Department of Neuroscience, Università Cattolica del Sacro Cuore, Rome, Italy, ${ }^{2}$ Fondazione Policlinico Universitario A. Gemelli IRCCS, Rome, Italy

Glucose metabolism derangement is critically involved in the age-related memory loss but the underlying molecular mechanisms are still poorly understood. In a mouse model of type 1 diabetes we found memory impairment associated with inhibition of the transcription factor CREB and alteration of pre- and post-synaptic protein expression in the hippocampus. Accordingly, glucose excess negatively affected activity-dependent CREB phosphorylation and CREB-mediated mRNA expression of synaptic proteins in hippocampal primary neurons. Specifically, glucose excess inhibited the activitydependent recruitment of CREB on the regulatory sequences of synaptotagmin (SYT) 2 and 4 promoters and the expression of SYT4 protein. As a result, high glucose affected both the frequency of miniature excitatory postsynaptic currents and NMDA receptormediated currents in autaptic hippocampal neuronal cultures. Collectively, our findings highlight novel mechanisms underlying hyperglycaemia-related memory loss, including CREB-dependent downregulation of synaptotagmin expression.

Keywords: synaptic vesicle release, hippocampus, type 1 diabetes, hyperglycaemia, synaptic proteins, memory loss, metabolism

\section{INTRODUCTION}

In response to physiological stimuli and environmental conditions, the central nervous system undergoes functional and structural changes (Pascual-Leone et al., 2005). Molecular mechanisms underlying synaptic transmission and plasticity play a pivotal role in the regulation of learning and memory. A plethora of synaptic proteins, including synaptophysin, synapsin family and the SNAP receptor (SNARE) complex regulates the fusion of neurotransmitter vesicles to the synaptic membrane and their release (Brose et al., 2019). Moreover, $\mathrm{Ca}^{2+}$ sensor proteins such as synaptotagmins are crucial for $\mathrm{Ca}^{2+}$-dependent exocytosis (Fernández-Chacón et al., 2001; Südhof and Rothman, 2009). In glutamatergic synapses, activity-dependent rapid changes in the composition of $\alpha$-amino-3-hydroxy-5-methyl-4-isoxazolepropionic acid (AMPA) and N-methyl$\mathrm{D}$-aspartate (NMDA) glutamate receptors at the postsynaptic compartment enhance the amplitude of postsynaptic responses and strengthen the synaptic functions (Zito and Svoboda, 2002).

Importantly, glucose metabolism derangement and type 2 diabetes negatively impact on synaptic plasticity and cognitive functions through multiple mechanisms including oxidative stress, 
endothelial dysfunctions, microglia activation and neurotrophin depletion (Kullmann et al., 2016; Duffy et al., 2019; Spinelli et al., 2019). However, how glucose excess affects synaptic transmission and neuron-to-neuron communication is still poorly understood. The transcription factor cAMP response element-binding protein (CREB) has been widely investigated as a metabolic sensor and regulator of glucose homeostasis in liver and fat tissue (Altarejos and Montminy, 2011), and as a master switch of $\mathrm{Ca}^{2+}$ and neurotrophin-triggered transcriptional programs regulating neuronal differentiation, survival, and plasticity in central and peripheral nervous systems (Riccio et al., 1999; Finkbeiner, 2000, Mantamadiotis et al., 2002). Furthermore, brain plasticity and high-order cognitive functions are as well influenced by nutrient cues and energy metabolism through CREB-dependent expression of genes involved in adult neurogenesis, chromatin silencing and neuronal metabolism (Fusco et al., 2012, 2016). Here we demonstrated that glucose overload inhibits CREB activity in hippocampal neurons and alters the expression of genes encoding pre- and post-synaptic proteins. High glucose concentration also impairs the spontaneous vesicle release and both the amplitude and the kinetics of NMDA receptor-mediated currents at the post-synaptic level. Finally, we identified synaptotagmin 2 and 4 (SYT2 and SYT4, respectively) as novel glucose-responsive CREB target genes involved in hyperglicaemia-dependent impairment of synaptic function.

\section{MATERIALS AND METHODS}

\section{Ethics Statement}

The animal study was reviewed and approved by the Ethics Committee of Università Cattolica del Sacro Cuore and were fully compliant with Italian (Ministry of Health guidelines, Legislative Decree No. 116/1992) and European Union (Directive No. 86/609/EEC) legislations on animal research.

\section{Animals}

Male C57BL/6 mice (30 days-old), derived from the Animal Facility of Università Cattolica del Sacro Cuore, were used and randomly assigned to two treatments: (i) intraperitoneal injection of saline (CTR, control) and (ii) intraperitoneal injection of streptozotocin (STZ). Mice were housed in groups (3-5 animals per cage) and they were daily monitored. To induce hyperglycaemia, mice were intraperitoneally injected with $50 \mathrm{mg} / \mathrm{Kg}$ of streptozotocin (Sigma-Aldrich) for five consecutive days. The drug was freshly prepared in $\mathrm{Na}^{+}$citrate solution buffered to $4.5 \mathrm{pH}$. Before each streptozotocin injection, animals were fasted for $6 \mathrm{~h}$. After each injection, mice were supplied with $10 \%$ sucrose water to avoid sudden hypoglycaemia post injection. Mice were tested for sufficient levels of hyperglycaemia at 2 weeks after last injection (defined as time 0 ) and only mice with plasma glucose levels higher than $300 \mathrm{mg} / \mathrm{dL}$ were used for experiments. Blood sugar dosages and behavioral analyses were performed at both 1 and 3 weeks from time 0 . Molecular analyses were performed on whole hippocampi collected 3 weeks from time 0 on different cohorts of mice. The animals were housed under a 12-h light-dark cycle at room temperature $\left(\mathrm{RT}: 19-22^{\circ} \mathrm{C}\right)$ and received both food and water ad libitum.

\section{Culture of Primary Neurons}

Primary cultures of hippocampal neurons were obtained from E18 C57BL/6 mice embryos according to standard procedures. Briefly, hippocampi were dissected and incubated for $10 \mathrm{~min}$ at $37^{\circ} \mathrm{C}$ in PBS containing $0.025 \%$ trypsin $/ 0.01 \%$ EDTA (Biochrom $\mathrm{AG})$. The tissue was then mechanically dissociated at room temperature $\left(23-25^{\circ} \mathrm{C}\right)$ using a fire-polished Pasteur pipette and the cell suspension was harvested and centrifuged at $100 \times g$ for $8 \mathrm{~min}$. The pellet was suspended in $88.8 \%(\mathrm{vol} / \mathrm{vol})$ minimum essential medium (Biochrom), 5\% FBS, 5\% (vol/vol) horse serum, $1 \%$ glutamine $(2 \mathrm{mM}), 0.2 \%$ gentamicin $(0.1 \mathrm{mg} / \mathrm{mL})$ and glucose $(25 \mathrm{mM})$. At $24 \mathrm{~h}$ after plating (1st day in vitro, DIV1), the culture medium was replaced with a medium containing $97.3 \%$ ( $\mathrm{vol} / \mathrm{vol}$ ) neurobasal medium (Invitrogen), 2\% (vol/vol) B-27 (Invitrogen), $0.5 \%$ glutamine $(2 \mathrm{mM})$, and $0.2 \%$ gentamicin $(0.1 \mathrm{mg} / \mathrm{mL})$. After $72 \mathrm{~h}$ (DIV4), the culture medium was replaced with a similar medium lacking glutamine and supplemented with $2 \mu \mathrm{M}$ cytosine $\beta$-D-arabinofuranoside to inhibit glial cell proliferation. Autaptic hippocampal neurons were prepared as previously described (Attar et al., 2012; Ripoli et al., 2013). In brief, cortical astrocytes from $\mathrm{P} 0-\mathrm{P} 2$ brains of $\mathrm{C} 57 \mathrm{BL} / 6$ mice were plated onto agarose-coated glass coverslips on which microislands where astrocytes could be grown were created by spraying a mixture of poly-D-lysine and collagen (both from Sigma). After 4 days, the medium (consisting of DMEM supplemented with $10 \%$ fetal bovine serum and antibiotics) was conditioned replacing half the medium volume with neuronal medium (Neurobasal medium, $2 \%$ B- $27,0.5 \%$ glutamine, and $1 \%$ penicillin-streptomycinneomycin antibiotic mixture). Hippocampal neurons from P0 to P2 C57BL/6 were plated onto glial microislands at low density $\left(25,000 / \mathrm{cm}^{2}\right)$ to obtain a ratio of one neuron per island. Both cultures (hippocampal neurons and autaptic hippocampal neurons) were maintained at $37^{\circ} \mathrm{C}$ in a humidified atmosphere of $5 \% \mathrm{CO}_{2}$ until experimental procedures. Every 3 days glucose levels in neuronal media were analyzed with glucometer. At DIV7 and DIV11 half the medium volume was replaced with fresh medium containing $25 \mathrm{mM}(\mathrm{HG})$ or $0-5.5 \mathrm{mM}(\mathrm{NG})$ in order to gradually decrease the level of glucose in NG samples and to obtain the experimental glucose concentration at DIV11. Molecular and electrophysiological experiments were performed at DIV14, after 3 days of HG $(25 \mathrm{mM})$ and NG $(5.5 \mathrm{mM})$. For molecular analyses, hippocampal neurons were stimulated with either $20 \mathrm{mM}$ potassium chloride (Sigma Aldrich) or $10 \mu \mathrm{M}$ forskolin (Sigma Aldrich). These compounds were applied for $30 \mathrm{~min}$ to investigate CREB phosphorylation and for $6 \mathrm{~h}$ to study gene expression modifications.

\section{Behavioral Experiments}

Behavioral tests were carried out from 9 a.m. to 4 p.m. and data were analyzed in blind using an automated video tracking system (Any-Maze ${ }^{\mathrm{TM}}$ ). Recognition memory was evaluated by novel object recognition (NOR) test. On first day, animals were familiarized for $10 \mathrm{~min}$ to the test arena $(45 \mathrm{~cm} \times 45 \mathrm{~cm})$. On second day (training session), they were allowed to explore two 
identical objects placed symmetrically in the arena for $10 \mathrm{~min}$. Mice exhibiting a total exploration time lower than $30 \mathrm{~s}$ or exploring one of two identical objects for more than $60 \%$ of the total exploration time during training session were excluded from the test. On third day (test session), a new object replaced one of the old objects. Animals were allowed to explore for $10 \mathrm{~min}$ and preference index, calculated as the ratio between time spent exploring the novel object and time spent exploring both objects, was used to measure recognition memory. To exclude place preference in the test session, the position of novel object was alternated when testing the different animals. All objects and the box were cleaned with $70 \%$ ethanol at the end of each test.

\section{Western Blotting}

Tissues (hippocampi) or cells (hippocampal neurons) were lysed in ice-cold lysis buffer $(\mathrm{NaCl} 150 \mathrm{mM}$, Tris- $\mathrm{HCl} 50 \mathrm{mM}$ $\mathrm{pH} 7.4$, EDTA $2 \mathrm{mM}$ ) containing $1 \%$ Triton $\mathrm{X}-100,0.1 \%$ SDS, $1 \times$ protease inhibitor cocktail (Sigma-Aldrich), $1 \mathrm{mM}$ sodium orthovanadate (Sigma-Aldrich) and $1 \mathrm{mM}$ sodium fluoride (Sigma-Aldrich). Cells were incubated for $10 \mathrm{~min}$ on ice with occasional vortexing and spun down at 22,000 $\times \mathrm{g}$, $4^{\circ} \mathrm{C}$. Supernatant was quantified for protein content (DC Protein Assay; Bio-Rad). Equal amounts of protein were diluted in Laemmli buffer, boiled and resolved by SDS-PAGE. The primary antibodies (available in Supplementary Table S1) were incubated overnight and revealed with HRP-conjugated secondary antibodies (Cell Signaling Technology Inc., Danvers, MA) and chemiluminescent substrates (Cyanagen). Band density was assessed by using UVItec Cambridge Alliance (Cambridge, United Kingdom). Protein expression levels were quantified by calculating the band intensity ratio of the target protein and actin (loading control) in each lane. Phosphorylation level of target proteins was quantified by calculating the band intensity ratio of phospho-target protein, target protein and actin (loading control) in each lane. In each bar graph, the mean value of controls was set to 1 and the expression or phosphorylation levels of target protein were shown as fold changes compared to the control (relative units). Images shown were cropped for presentation with no manipulations.

\section{Real-Time PCR}

Quantitative Real-Time PCR (qRT-PCR) amplifications were performed using SYBR GREEN qPCR Master Mix (Fisher Molecular Biology) on AB7500 instrument (Life Technologies) according to the manufacturer's instructions. The thermal cycling profile featured a pre-incubation step of $94^{\circ} \mathrm{C}$ for $10 \mathrm{~min}$, followed by 40 cycles of denaturation $\left(94^{\circ} \mathrm{C}, 15 \mathrm{~s}\right)$, annealing $\left(55^{\circ} \mathrm{C}, 30 \mathrm{~s}\right)$, and elongation $\left(72^{\circ} \mathrm{C}, 20 \mathrm{~s}\right)$. Melting curves were subsequently generated $\left(94^{\circ} \mathrm{C}\right.$ for $15 \mathrm{~s}, 50^{\circ} \mathrm{C}$ for $30 \mathrm{~s}$, slow heating to $94^{\circ} \mathrm{C}$ in increments of $\left.0.5^{\circ} \mathrm{C}\right)$.

Melting-curve analyses confirmed that only single products had been amplified. The primer sequences are shown in Supplementary Table S2. All data were normalized by reference to the amplification levels of the Gapdh gene; a reference dye was included in the SYBR master mix. RNA of all samples was analyzed in triplicate. The thresholds calculated by the software were used to determine specific mRNA expression levels using the cycle-at-threshold (Ct) method, and all results are expressed as fold changes (compared to control) for each transcript, employing the $2-\Delta \Delta \mathrm{Ct}$ approach.

\section{Immunocytochemistry}

Hippocampal neurons were fixed in PBS solution (4\% PFA, $\mathrm{pH}$ 7.4; Sigma-Aldrich) for $15 \mathrm{~min}$ at RT. Neurons were then permeabilized with $0.2 \%$ Triton X-100 (Sigma-Aldrich) for $15 \mathrm{~min}$, blocked for $60 \mathrm{~min}$ in 5\% NGS, and then incubated overnight at $4^{\circ} \mathrm{C}$ with anti-MAP2 (HM-2 clone, 1:400, SigmaAldrich). Cells were subsequently incubated for $90 \mathrm{~min}$ at RT with secondary antibody (Alexa-Fluor Donkey Anti-Mouse 1:1000). Finally, nuclei were counterstained with $4^{\prime}, 6$ - diamidino-2phenylindole (DAPI, $0.5 \mu \mathrm{g}$ per $\mathrm{mL}$ for $10 \mathrm{~min}$; Thermo Fisher), and cells were coverslipped with ProLong Gold anti-fade reagent (Thermo Fisher). Images of $1024 \times 1024$ pixels were obtained with an A1 MP, Nikon confocal microscope (Tokyo, Japan) equipped with $20 \times$ and $40 \times$ magnification objectives (numerical aperture 1.4), plus additional magnification.

\section{Electrophysiology in Autaptic Microcultures}

All electrophysiological recordings were performed using wholecell patch clamp. Recordings were obtained with an Axopatch 200B amplifier (Molecular Devices), and stimulation and data acquisition were performed with the Digidata 1200 series interface and pCLAMP 11 software (Molecular Devices). Basal synaptic transmission was studied from 14 to 21 DIV using the patch-clamp technique in the whole-cell configuration as previously described (Ripoli et al., 2014). Cells were approached under DIC with 3-5 M $\Omega$ pipettes pulled from borosilicate glass (Warner Instruments, Inc) using a vertical Narishige PC-10 puller (Japan) and filled with an internal solution containing (in $\mathrm{mM}$ ): $146 \mathrm{~K}$-gluconate, $18 \mathrm{HEPES}, 1$ EGTA, $4.6 \mathrm{MgCl}_{2}$, $4 \mathrm{NaATP}$, $0.3 \mathrm{Na}_{2} \mathrm{GTP}, 15$ creatine phosphate, and $5 \mathrm{U} / \mathrm{ml}$ phosphocreatine kinase. External Tyrode's solution containing the following (in $\mathrm{mM}$ ): $140 \mathrm{NaCl}, 2 \mathrm{KCl}, 10 \mathrm{HEPES}, 10$ glucose, $4 \mathrm{MgCl}_{2}$, and $4 \mathrm{CaCl}_{2}, \mathrm{pH} 7.4,312 \mathrm{mOsm}$. NMDA receptor-mediated currents were evoked using Mg-free Tyrode's solution containing $10 \mathrm{mM}$ of the AMPA receptor blocker NBQX (Tocris Bioscience). Neurons were maintained at $-70 \mathrm{mV}$ holding potentials, and EPSCs were elicited with stimuli mimicking action potentials $(2 \mathrm{~ms}$ at $0 \mathrm{mV}$ ) delivered every $10 \mathrm{~s}$ or $20 \mathrm{~s}$. The paired-pulse ratio consisted of the ratio of the amplitude of the second EPSC to that of the first recorded at $50 \mathrm{~ms}$ intervals (Fattorini et al., 2019). To obtain the AMPA/NMDA ratio, evoked responses were recorded successively from the same cell. The amplitude and frequency of miniature excitatory postsynaptic currents (mEPSCs) were evaluated in $60 \mathrm{~s}$ recordings. The decay time was estimated by fitting a single exponential to the $10-90 \%$ decay-phase. We monitored the access resistance and membrane capacity before and at the end of the experiments to ensure recording stability and the health of studied cells. Whole-cell recordings were performed 5-15 min after the culture medium replacement with external Tyrode's solution. The culture plates were changed every half-hour. All experiments were performed at RT. 


\section{Chromatin Immunoprecipitation}

Chromatin immunoprecipitation (ChIP) assays were performed as previously described (Fusco et al., 2019). Neurons were resuspended in $200 \mu \mathrm{l}$ lysis buffer containing $1 \%$ SDS, $50 \mathrm{mM}$ Tris-HCl pH 8.0, and $10 \mathrm{mM}$ EDTA and sonicated on ice with six 10-s pulses with a 20-s interpulse interval. Sample debris was removed by centrifugation and supernatants were precleared with protein-G Sepharose 4B beads (Sigma-Aldrich) for $1 \mathrm{~h}$ at $4^{\circ} \mathrm{C} .2 \mu \mathrm{g}$ of anti-CREB or control IgG were added overnight at $4^{\circ} \mathrm{C}$. Immune complexes were collected by incubation with protein-G Sepharose $4 \mathrm{~B}$ beads for $2 \mathrm{~h}$ at $4^{\circ} \mathrm{C}$. After seven sequential washes, immune complexes were eluted from beads by vortexing in elution buffer ( $1 \%$ SDS and $\mathrm{NaHCO}_{3} 0.1 \mathrm{M}$; $\mathrm{pH}$ 8.0). $\mathrm{NaCl}$ was added (final concentration $0.33 \mathrm{M}$ ), and cross-linking was reversed by incubation overnight at $65^{\circ} \mathrm{C}$. DNA fragments were purified by using the PCR DNA fragments purification kit (Geneaid). The primer sequences are shown in Supplementary Table S2.

PCR conditions and cycle numbers were determined empirically and each PCR reaction was performed in triplicate. Data are expressed as percentage of input calculated by the "Adjusted input value" method according to the manufacturer's instructions (ThermoFisher Scientific ChIP Analysis). To determine the Adjusted input the $\mathrm{Ct}$ value of input was subtracted by 6.644 (i.e., $\log 2$ of 100). Next, the percent input of samples was estimated using the formula: $100^{*} 2^{\wedge}$ (Adjusted input - $\mathrm{Ct}(\mathrm{ChIP})$. The percent input of IgG samples was calculated using the formula $100^{*} 2^{\wedge}$ (Adjusted input - $\mathrm{Ct}(\operatorname{IgG})$.

\section{Statistical Analysis}

Sample sizes were chosen with adequate power (0.8) according to results of prior pilot data sets or studies, including our own, which used similar methods or paradigms. Sample estimation and statistical analyses were performed using SigmaPlot 12 software. Data were first tested for equal variance and normality (Shapiro-Wilk test) and the appropriate statistical tests were chosen. The statistical tests used (i.e., Student's $t$-test, twoway ANOVA) are indicated in the main text and in the corresponding figure legends for each experiment. $\mathrm{N}$ numbers are reported in the figure legends. Degrees of freedom are $\mathrm{n}-1$ for each condition in both unpaired $t$-test and ANOVA tests. Post-hoc multiple comparisons were performed with Bonferroni correction. All statistical tests were two-tailed and the level of significance was set at 0.05 . Results are shown as mean \pm SEM.

\section{RESULTS}

\section{Hyperglicemia Reduces the Expression of Pre- and Post-synaptic Proteins in the Hippocampus}

Glucose metabolism dysregulation has been reported to affect synaptic function (Zhong et al., 2019). Previous studies demonstrated alterations of hippocampus-dependent-learning and memory in experimental models of hyperglycaemia (Gispen and Biessels, 2000) but the underlying molecular mechanisms remain still poorly understood. To investigate the effects of glucose excess on the expression of pre- and post-synaptic proteins in the hippocampus, we set up an in vivo model of streptozotocin (STZ)-induced hyperglycaemia. First, we evaluated glucose plasma levels and hippocampus-dependent cognitive function one and 3 weeks after the onset of hyperglicaemia. As expected, multiple STZ injections induced elevated values of fasting glycaemia and this alteration persisted after 3 weeks $\left(400.44 \pm 8.29 \mathrm{mg} \mathrm{dL}^{-1}\right.$ vs $102.77 \pm 6.06 \mathrm{mg}$ $\mathrm{dL}^{-1}, p=1.11 \times 10^{-15}$ after 1 week; $406.22 \pm 9.38 \mathrm{mg}$ $\mathrm{dL}^{-1}$ vs $107.00 \pm 3.28 \mathrm{mg} \mathrm{dL}-1, p=6.09 \times 10^{-16}$ after 3 weeks; Figure 1A). More importantly, STZ mice already showed lower preference index than controls after the first week of high glucose levels, and their performances in novel object recognition (NOR) task even got worse after 3 weeks of hyperglicaemia (after 1 week: preference index $59.0 \pm 0.9 \%$ vs $68.5 \pm 0.5 \%, p=7.05 \times 10^{-8}$, exploration time toward novel object/old object $40.7 \pm 6.7 \mathrm{~s}$ $/ 29.5 \pm 8.2 \mathrm{~s}$ vs $42.2 \pm 6.5 \mathrm{~s} / 19.4 \pm 4.2 \mathrm{~s}$; after 3 weeks: preference index $56.0 \pm 0.7 \%$ vs $69.0 \pm 1.1 \%$, $p=1.23 \times 10^{-8}$, exploration time toward novel object/old object $41.1 \pm 4.4 \mathrm{~s} / 32.3 \pm 4.6 \mathrm{~s}$ vs $47.1 \pm 4.9 \mathrm{~s} / 21.1 \pm 3.2 \mathrm{~s}$ Figure 1B).

We also investigated the expression of glutamate receptor subunits and the activity-dependent phosphorylation of neuroplasticity proteins CaMKII $\alpha$ and CREB in the hippocampus of hyperglicaemic mice. The immunoblot analysis of hippocampal lysates from STZ mice revealed lower expression of NMDA receptor subunits GluN1 and GluN2a and AMPA receptor subunit GluA2 compared to controls $(-41 \pm 5,-67 \pm 8$, and $-47 \pm 4 \%$, respectively, $p<0.001$ for all proteins; Figure 1C). In addition, STZ treatment reduced the activatory phosphorylation of transcription factor CREB on serine $133\left(\right.$ CREB $\left.^{\text {Ser133 }}\right)(-75 \pm 7 \%, p=0.0004$; Figure 1C). Instead, no significant changes were observed for the expression of GluN2b and GluA1 and the activatory phosphorylation of CaMKII $\alpha$ on threonine 286 (Figure 1C). CREB-mediated transcription of presynaptic proteins has been demonstrated to promote synaptic enhancement and memory (Wagatsuma et al., 2006). Therefore, we analyzed the mRNA expression of several synaptic transmissionassociated proteins in the hippocampus of STZ mice. We found lower expression of synaptotagmin 2 and 4 (SYT2 and SYT4, respectively) in hyperglycaemic mice $(-49 \pm 5 \%$, $p=3.34 \times 10^{-5}$ and $-56 \pm 6 \%, p=3.96 \times 10^{-5}$, respectively; Figure 1D), whereas we did not detect any significant changes of synaptotagmin 1 (SYT1), synaptophysin (SYP) and synapsin 1 (SYN1). We also found a significant decrease of Bdnf expression in the hippocampus of STZ mice compared to controls $\left(-59 \pm 5 \%, p=7.12 \times 10^{-5}\right.$; Figure 1D). Collectively, in vivo data demonstrated that STZ-induced hyperglycaemia reduced CREB activation and the expression of hippocampal pre- and post-synaptic proteins involved in synaptic function and memory. 
A

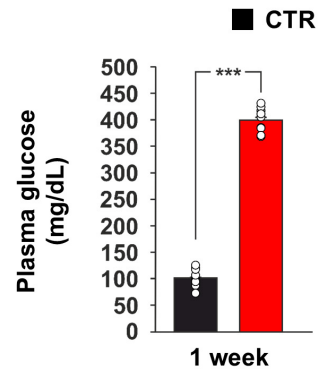

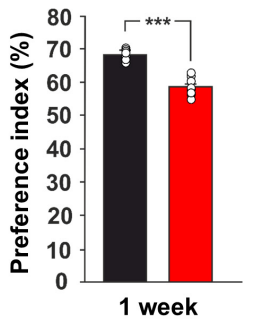

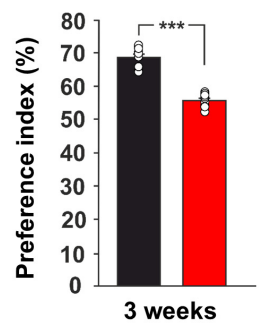

C

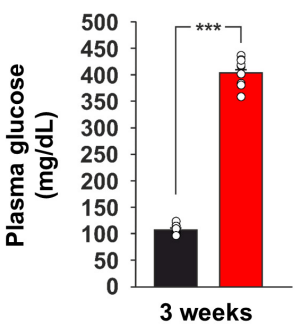

CTR

STZ

1\# 2\# 3\# 4\# 1\# 2\# 3\# 4\#

\begin{tabular}{|c|c|}
\hline a- GluN1 & 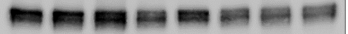 \\
\hline$\alpha-$ GluN2a & $-\cdots \cdots-\cdots$ \\
\hline$\alpha-$ GluN2b & 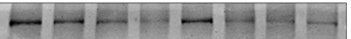 \\
\hline a- GluA1 & $-m--m-m$ \\
\hline$\alpha$ - GluA2 & 브르를 \\
\hline$\alpha-p C_{r e b}{ }^{S 133}$ & 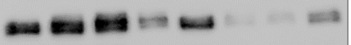 \\
\hline$\alpha-$ Creb & 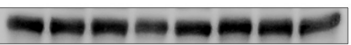 \\
\hline$\alpha-p C a M K I I{ }^{T 286}$ & $--\cdots \cdots$ \\
\hline$\alpha-$ CaMKII & 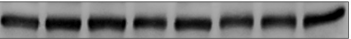 \\
\hline a- Actin & $-\cdots-\cdots$ \\
\hline
\end{tabular}
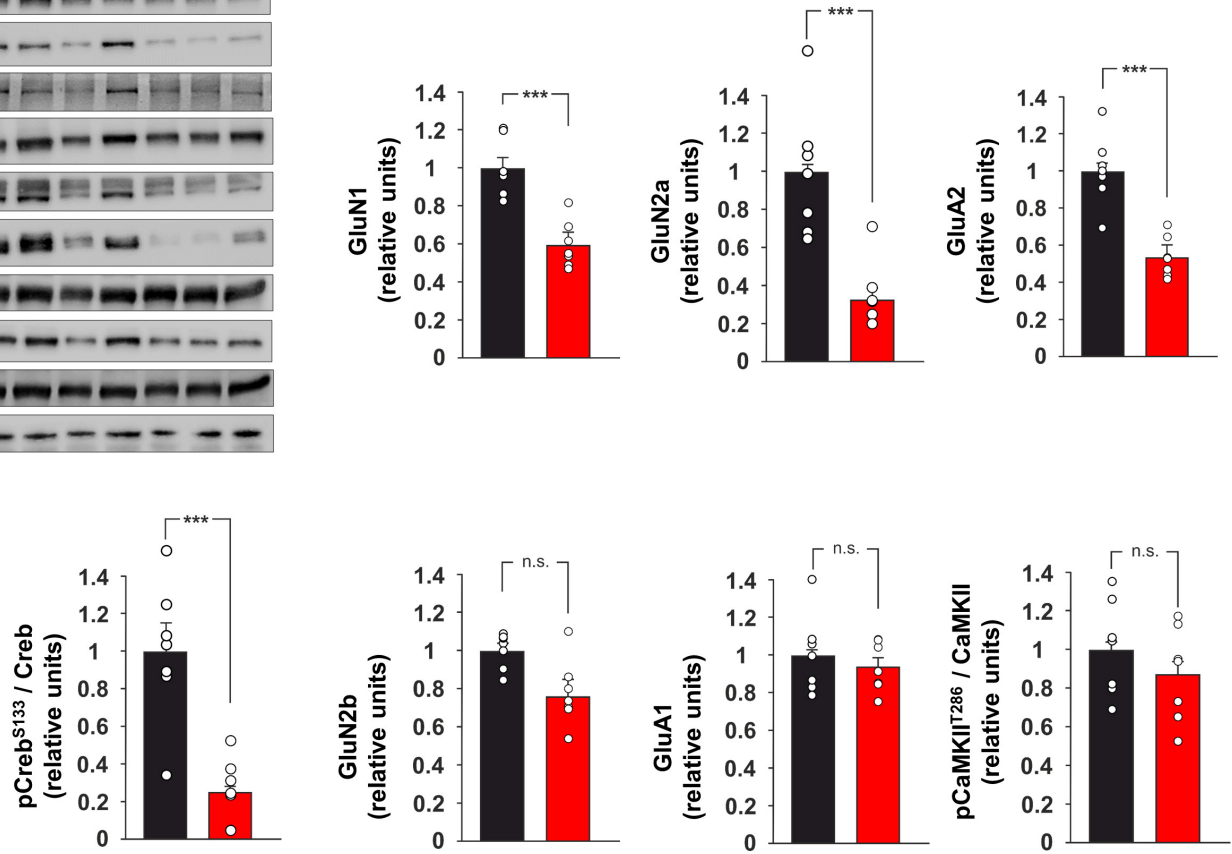

D
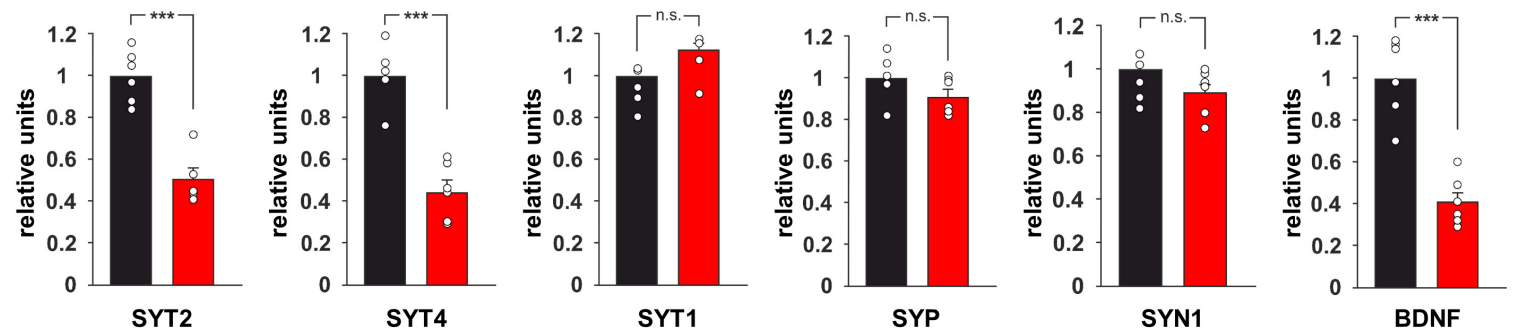

FIGURE 1 | Hyperglicaemia affects the expression of pre- and post-synaptic proteins in the hippocampus. (A) Plasma levels of glucose in C57BL/6 mice i.p. injected with saline (CTR) or streptozotocin (STZ, $50 \mathrm{mg} / \mathrm{Kg} /$ day for 5 days). Glycaemia levels were detected after 1 or 3 weeks from the onset of hyperglycaemia in STZ mice ( $n=9$ mice per group; statistics by unpaired Student's $t$-test). (B) Preference for the novel object in the NOR paradigm after 1 or 3 weeks from the onset of hyperglycaemia in CTR and STZ mice ( $n=9$ mice; statistics by unpaired Student's $t$-test). (C) Immunoblot analysis and bar graphs showing the expression of GluN1, GluN2a, GluN2b, GluA1, GluA2 and the phosphorylation of both Creb on serine 133 (Creb ${ }^{\mathrm{S} 133}$ ) and CaMKII on threonine 286 (CaMKII ${ }^{T 286}$ ) in the hippocampus of CTR and STZ mice ( $n=7$ mice; statistics by unpaired Student's $t$-test). (D) mRNA expression of synaptotagmin 1,2 and 4 (SYT1, SYT2, and SYT4, respectively), synaptophysin (SYP), synapsin 1 (SYN1) and BDNF in the hippocampus of CTR and STZ mice ( $n=6$ mice; statistics by unpaired Student's $t$-test). Real Time analysis was performed in triplicate. Gene expression was normalized to Gapdh. Data are expressed as mean \pm SEM. ${ }^{*} p<0.05 ;{ }^{* \star *} p<0.001$; n.s. not significant. 


\section{Glucose Excess Inhibits CREB-Dependent Gene Expression}

To deeply investigate the effect of hyperglycaemia on CREB transcriptional activity, we set up an in vitro model of hippocampal primary neurons cultivated in media containing either normal (NG) or high glucose (HG) concentrations (1 g/L or $4.5 \mathrm{~g} / \mathrm{L}$, respectively; Figure $\mathbf{2 A}$ ). In neurons, synaptic activity enhances the intracellular concentration of $\mathrm{Ca}^{2+}$ and cyclic adenosine monophosphate (cAMP), both leading to phosphorylation and activation of CREB (Deisseroth et al., 1996). Accordingly, compounds inducing intracellular increase of either $\mathrm{Ca}^{2+}(20 \mathrm{mM} \mathrm{KCl})$ or cAMP $(10 \mu \mathrm{M}$ forskolin [Fsk]) induced $\mathrm{CREB}^{\mathrm{Ser} 133}$ phosphorylation in neurons exposed to normal glucose levels $\left(F_{2.71}=16.82,+49 \pm 12 \% \mathrm{NG}_{\mathrm{KCl}}\right.$ vs $\mathrm{NG}_{\mathrm{NT}}, p=0.011 ;+99 \pm 18 \% \mathrm{NG}_{\mathrm{Fsk}}$ vs $\mathrm{NG}_{\mathrm{NT}}, p=0.004$, Figure 2B). Conversely, HG significantly reduced the basal phosphorylation levels of CREB and inhibited its activation upon $\mathrm{KCl}$ stimulation $\left(-34 \pm 6 \% \mathrm{HG}_{\mathrm{NT}}\right.$ vs $\mathrm{NG}_{\mathrm{NT}}, p=0.009$; $+33 \pm 9 \% \mathrm{HG}_{\mathrm{KCl}}$ vs $\mathrm{HG}_{\mathrm{NT}}, p=0.088$, Figure $\left.2 \mathrm{~B}\right)$. We also analyzed the mRNA expression of both CREB target genes and synaptic proteins that we found downregulated in the hippocampus of STZ mice. In standard conditions, both $\mathrm{KCl}$

\section{A}

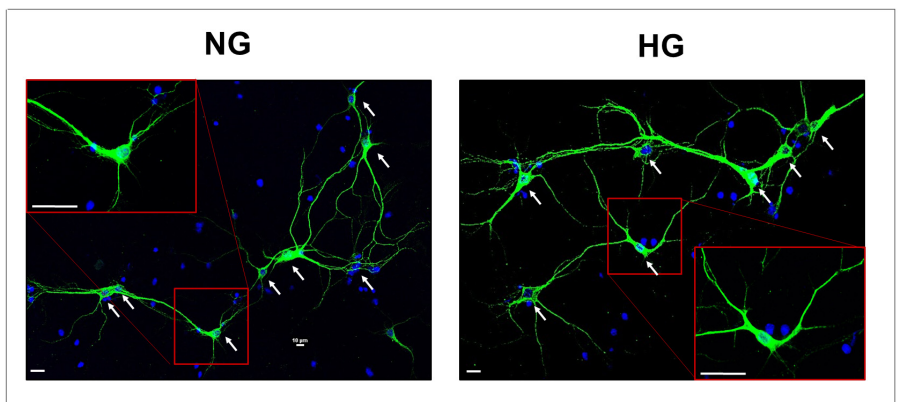

B
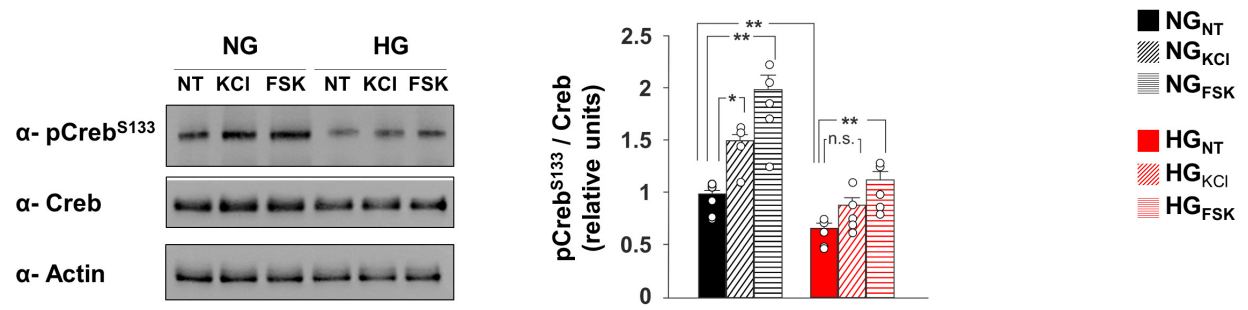

C
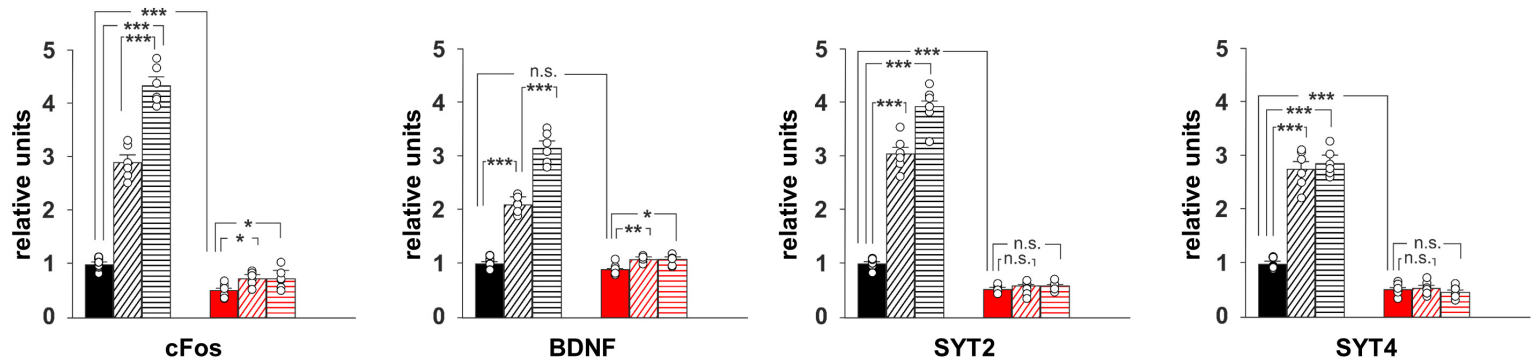

FIGURE 2 | Glucose excess impairs both CREB phosphorylation and expression of plasticity-related genes in neurons. (A) Representative images of hippocampal neurons cultivated in media containing normal (NG, $1.0 \mathrm{~g} / \mathrm{L}$ ) or high glucose (HG, $4.5 \mathrm{~g} / \mathrm{L})$ levels. Scale bar: $50 \mu \mathrm{M}$. (B) Immunoblot analyses and bar graphs showing CrebS133 phosphorylation in NG or HG neurons treated with vehicle (NT), $20 \mathrm{mM}$ potassium chloride (KCl) or $10 \mu \mathrm{M}$ forskolin (Fsk). The experiment was repeated five times (statistics by two-way ANOVA and Bonferroni post hoc). (C) mRNA expression of cFos, BDNF, SYT2, and SYT4 in NH and HG neurons. Real Time analysis was performed in triplicate. Gene expression was normalized to Gapdh. The experiment was repeated six times using independent RNA samples (statistics by two-way ANOVA and Bonferroni post hoc). Data are expressed as mean $\pm \mathrm{SEM}$. ${ }^{\star} p<0.05 ;{ }^{* \star} p<0.01 ;{ }^{* \star *} p<0.001 ;$ n.s. not significant. 
and Fsk largely enhanced the transcription of CREB targets c-Fos and Bdnf, whereas this enhancement was cut down by HG treatment $\left(F_{2.60}=270.15\right.$ for $\mathrm{cFos},+189 \pm 14 \% \mathrm{NG}_{\mathrm{KCl}}$ vs $\mathrm{NG}_{\mathrm{NT}}, p=8.39 \times 10^{-6} ;+334 \pm 16 \% \mathrm{NG}_{\mathrm{Fsk}}$ vs $\mathrm{NG}_{\mathrm{NT}}$, $p=5.86 \times 10^{-7} ;+48 \pm 5 \% \mathrm{HG}_{\mathrm{KCl}}$ vs $\mathrm{HG}_{\mathrm{NT}}, p=0.012$; $+48 \pm 8 \% \mathrm{HG}_{\mathrm{Fsk}}$ vs $\mathrm{HG}_{\mathrm{NT}}, p=0.038 ; F_{2.60}=191.32$ for Bdnf, $+109 \pm 7 \% \mathrm{NG}_{\mathrm{KCl}}$ vs $\mathrm{NG}_{\mathrm{NT}}, p=1.06 \times 10^{-7} ;+215 \pm 13 \%$ $\mathrm{NG}_{\text {Fsk }}$ vs $\mathrm{NG}_{\mathrm{NT}}, p=6.85 \times 10^{-7} ;+20 \pm 2 \% \mathrm{HG}_{\mathrm{KCl}}$ vs $\mathrm{HG}_{\mathrm{NT}}, p=0.006 ;+19 \pm 4 \% \mathrm{HG}_{\mathrm{Fsk}}$ vs $\mathrm{HG}_{\mathrm{NT}}, p=0.015$; Figure 2C). Moreover, molecules activating CREB enhanced the expression of both SYT2 and SYT4 genes. More importantly, glucose excess lowered the transcription of synaptotagmins and abolished their CREB activity-related upregulation reproducing in vitro the molecular changes observed in vivo $\left(F_{2.60}=286.79\right.$ for SYT2, $+203 \pm 14 \% \mathrm{NG}_{\mathrm{KCl}}$ vs $\mathrm{NG}_{\mathrm{NT}}, p=5.36 \times 10^{-6}$; $+292 \pm 16 \% \mathrm{NG}_{\mathrm{Fsk}}$ vs $\mathrm{NG}_{\mathrm{NT}}, p=1.57 \times 10^{-6} ;-49 \pm 3 \%$ $\mathrm{HG}_{\mathrm{NT}}$ vs $\mathrm{NG}_{\mathrm{NT}}, p=6.82 \times 10^{-6} ; \mathrm{HG}_{\mathrm{KCl}}$ vs $\mathrm{HG}_{\mathrm{NT}}, p=0.955$; $\mathrm{HG}_{\mathrm{Fsk}}$ vs $\mathrm{HG}_{\mathrm{NT}}, p=0.254 ; F_{2.60}=188.26$ for SYT $4,+176 \pm 16 \%$ $\mathrm{NG}_{\mathrm{KCl}}$ vs $\mathrm{NG}_{\mathrm{NT}}, p=2.24 \times 10^{-5} ;+187 \pm 11 \% \mathrm{NG}_{\mathrm{Fsk}}$ vs $\mathrm{NG}_{\mathrm{NT}}, p=5.37 \times 10^{-7} ;-49 \pm 5 \% \mathrm{HG}_{\mathrm{NT}}$ vs $\mathrm{NG}_{\mathrm{NT}}$, $p=1.72 \times 10^{-5} ; \mathrm{HG}_{\mathrm{KCl}}$ vs $\mathrm{HG}_{\mathrm{NT}}, p=0.711 ; \mathrm{HG}_{\mathrm{Fsk}}$ vs $\mathrm{HG}_{\mathrm{NT}}$, $p=0.511$; Figure 2C). Our data indicate that HG negatively impacts on CREB phosphorylation and its transcriptional activity in hippocampal neurons, correlating with the impairment of synaptic protein expression.

\section{HG Inhibited the Recruitment of CREB on Both SYT2 and SYT4 Promoters}

The transcription factor CREB modulates synaptic activity by modifying its binding on the promoters of neuronal genes and regulating their expression (West and Greenberg, 2011). Our data suggested that SYT2 and SYT4 might represent novel molecular targets of CREB and be involved in the HG-related alteration of synaptic function. To verify whether the HG-dependent inhibition of CREB activity was implicated in the changes of SYT2 and SYT4 expression, we first analyzed the regulatory sequences of these genes. The bioinformatics analysis revealed the presence of several putative cAMP Responsive Elements (CRE) on the regulatory sequences of both SYT2 and SYT4 (Figure 3A). Chromatin immunoprecipitation experiments from hippocampal neurons showed that CREB binds the same genomic region in a fashion inducible by $\mathrm{KCl}$ and Fsk $\left(F_{2.60}=102.19\right.$ for SYT2, $+256 \pm 31 \% \mathrm{NG}_{\mathrm{KCl}}$ vs $\mathrm{NG}_{\mathrm{NT}}$, $p=2.87 \times 10^{-4} ;+308 \pm 25 \% \mathrm{NG}_{\mathrm{Fsk}} \mathrm{vs} \mathrm{NG}_{\mathrm{NT}}, p=4.63 \times 10^{-5}$; $F_{2.60}=99.53$ for SYT4, $+229 \pm 23 \% \mathrm{NG}_{\mathrm{KCl}}$ vs $\mathrm{NG}_{\mathrm{NT}}$, $p=4.5 \times 10^{-5} ;+257 \pm 25 \% \mathrm{NG}_{\mathrm{Fsk}}$ vs $\mathrm{NG}_{\mathrm{NT}}, p=3.47 \times 10^{-5}$; Figure 3B). Moreover, glucose excess affected the recruitment of transcription factor on the promoters of SYT2 and SYT4 in both basal and inducible conditions $\left(F_{2.60}=102.19\right.$ for SYT2, $-51 \pm 8 \% \mathrm{HG}_{\mathrm{NT}}$ vs $\mathrm{NG}_{\mathrm{NT}}, p=3.28 \times 10^{-4} ; \mathrm{HG}_{\mathrm{KCl}}$ vs $\mathrm{HG}_{\mathrm{NT}}$, $p=0.422 ; \mathrm{HG}_{\mathrm{Fsk}}$ vs $\mathrm{HG}_{\mathrm{NT}}, p=0.732 ; F_{2.60}=99.53$ for SYT4, $-40 \pm 8 \% \mathrm{HG}_{\mathrm{NT}}$ vs $\mathrm{NG}_{\mathrm{NT}}, p=3.61 \times 10^{-3} ; \mathrm{HG}_{\mathrm{KCl}}$ vs $\mathrm{HG}_{\mathrm{NT}}$, $p=0.740 ; \mathrm{HG}_{\mathrm{Fsk}}$ vs $\mathrm{HG}_{\mathrm{NT}}, p=0.620$; Figure 3B). Accordingly, CREB-activating stimuli induced SYT4 expression in NG-treated hippocampal neurons, whereas HG decreased SYT4 at protein level and inhibited its Fsk-dependent upregulation $\left(F_{2.71}=49.66\right.$,
$+43 \pm 4 \% \mathrm{NG}_{\mathrm{KCl}}$ vs $\mathrm{NG}_{\mathrm{NT}}, p=0.0019 ;+136 \pm 15 \% \mathrm{NG}_{\mathrm{Fsk}}$ vs $\mathrm{NG}_{\mathrm{NT}}, p=2.29 \times 10^{-5} ;-22 \pm 2 \% \mathrm{HG}_{\mathrm{NT}}$ vs $\mathrm{NG}_{\mathrm{NT}}$, $p=0.018 ;+21 \pm 11 \% \mathrm{HG}_{\mathrm{Fsk}}$ vs $\mathrm{HG}_{\mathrm{NT}}, p=0.089$; Figure $3 \mathrm{C}$ ). Moreover, SYT4 expression was significantly reduced in the hippocampi of hyperglycaemic mice $(-32 \pm 9 \%, p=0.0102$; Figure 3D). Collectively, our findings identify SYT2 and SYT4 as novel activity-dependent targets of CREB and indicate the CREB-dependent downregulation of vesicle release as a potential mechanism leading HG-dependent impairment of glutamatergic synaptic transmission.

\section{HG Alters the Basal Glutamatergic Synaptic Transmission in Autaptic Hippocampal Neurons}

Our molecular data demonstrate that glucose excess can alter the expression of pre- and post-synaptic proteins in hippocampal neurons. To evaluate the functional role of glucose dyshomeostasis on glutamatergic synaptic transmission, we performed patch-clamp experiments in autaptic hippocampal neuronal cultures grown in NG or HG conditions. First, we measured the membrane capacitance of autaptic hippocampal neurons that was unchanged by $\mathrm{HG}$ treatment $(90.5 \pm 2.9 \mathrm{pF}$ in NG condition $v s 94.8 \pm 3.0 \mathrm{pF}$ in $\mathrm{HG}$ condition, $p=0.3994$; Figure 4A).

Glucose overload did not affect evoked basal synaptic transmission, measured as the amplitude of excitatory postsynaptic currents (EPSCs) elicited by stimuli mimicking action potentials $(5.0 \pm 0.4 \mathrm{nA}$ in $\mathrm{NG}$ condition $v s 5.6 \pm 0.5$ $\mathrm{nA}$ in HG condition, $p=0.4155$; Figures 4B,C). Analysis of mEPSCs in autapses exposed to $H G$ revealed a significant decrease in the mEPSC frequency $(5.9 \pm 0.6 \mathrm{~Hz}$ in NG condition vs $3.2 \pm 0.4 \mathrm{~Hz}$ in HG condition, $p=0.0011$; Figures 4D-F) whereas the mean amplitude and the kinetics of mEPSCs (i.e., rise and decay time constants) were unaffected (mEPSC amplitude: $21.5 \pm 1.7 \mathrm{pA}$ in NG condition vs $22.0 \pm 2.0 \mathrm{pA}$ in HG condition, $p=0.8928$, Figures 4D,E,G; mEPSC rise time: $1.1 \pm 0.1 \mathrm{~ms}$ in $\mathrm{NG}$ condition vs $1.0 \pm 0.1 \mathrm{~ms}$ in $\mathrm{HG}$ condition, $p=0.5279$; mEPSC decay time $3.5 \pm 0.2 \mathrm{~ms}$ in NG condition vs $3.7 \pm 0.2$ in $\mathrm{HG}$ condition, $p=0.2995)$. To test whether the decrease in mEPSC frequency reflected a change in presynaptic vesicle release, we studied the paired-pulse ratio in response to two depolarizing stimuli delivered at $50 \mathrm{~ms}$ interval. The paired pulse ratio was not significantly different in NG and $\mathrm{HG}$ conditions $(67.3 \pm 4.9 \%$ $[\mathrm{n}=10]$ and $61.7 \pm 6.4 \%[\mathrm{n}=11]$, respectively, $\mathrm{p}=0.5952)$, indicating that the HG-related depression of mEPSCs frequency was not due to changes in the initial release probability of presynaptic vesicles.

To extend our analysis to the postsynaptic side, we recorded the responses to glutamate-receptor activation by applying $100 \mu \mathrm{M}$ glutamate through the extracellular solution perfusing the recorded neuron. In line with results on evoked EPSCs, the amplitude of the glutamatergic receptor-mediated current was not significantly different in autaptic neurons cultivated in NG or HG conditions ( $4.1 \pm 0.4 \mathrm{nA}$ vs $4.0 \pm 0.5 \mathrm{nA}$, respectively, $\mathrm{n}=14$ each condition, $p=0.9910)$. Of note, 
A

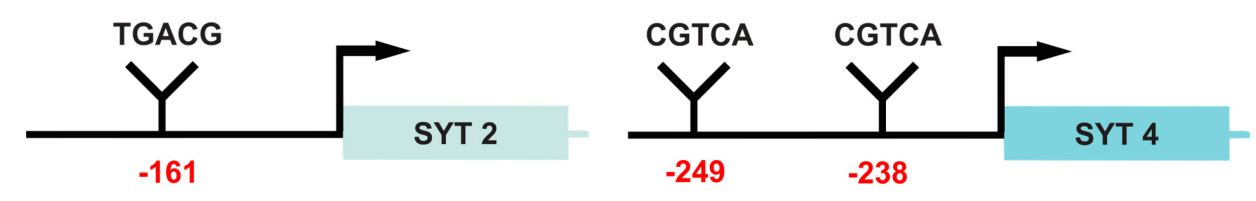

B
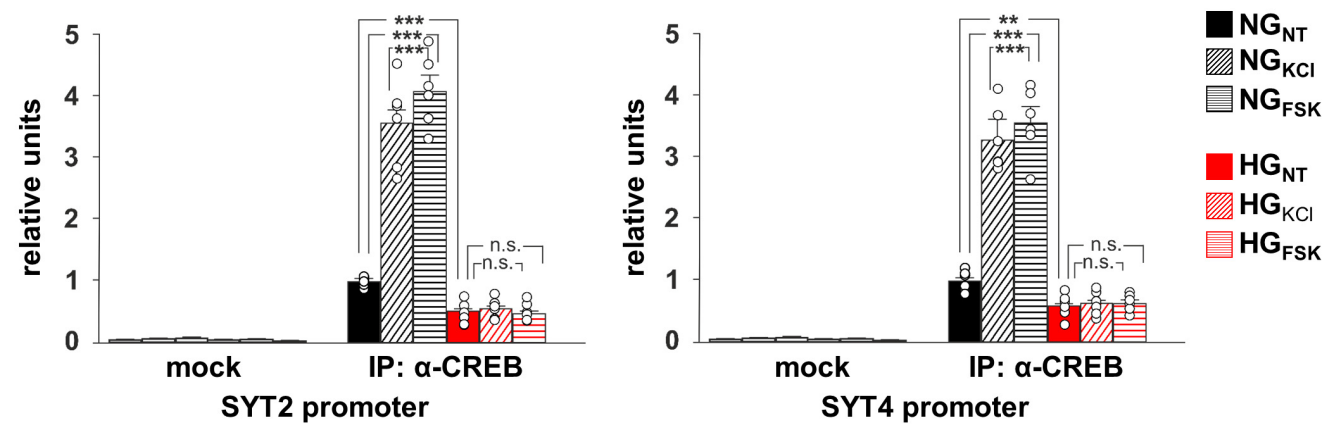

C

NG

HG

NT KCl FSK NT KCl FSK

$\alpha$ - SYT4

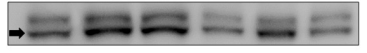

$\alpha-$ Actin
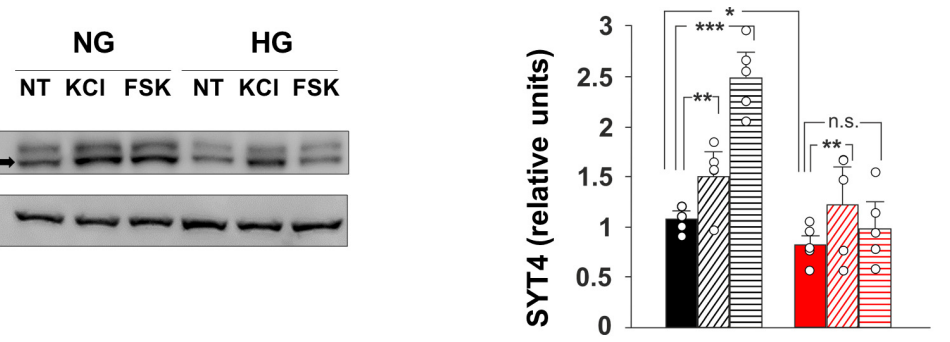

$\mathbf{N G}_{\mathrm{NT}}$

U/A $\mathbf{N G}_{\mathrm{KCl}}$

NG ${ }_{\text {FSK }}$

$\mathrm{HG}_{\mathrm{NT}}$

$\mathrm{HG}_{\mathrm{KCl}}$

HG $_{\mathrm{FSK}}$

D
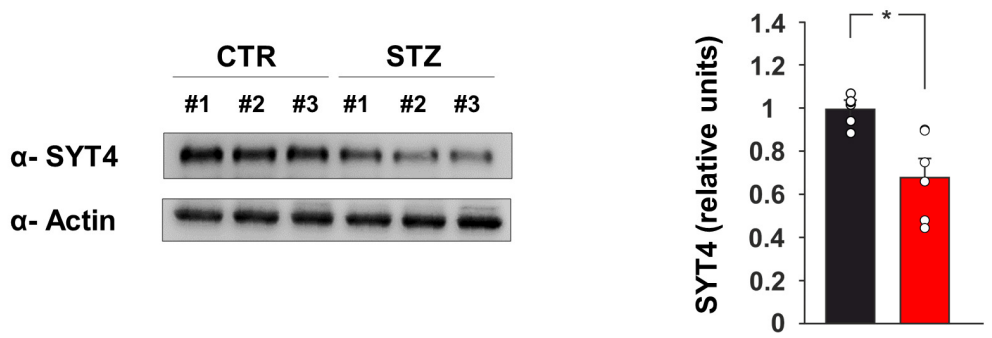

CTR

STZ

FIGURE 3 | CREB regulates SYT4 in a glucose-dependent fashion. (A) Schematic representation of putative CRE regions identified on the promoters of SYT2 ( -161 bp from transcription start site) and SYT4 (-249 and -238 bp upstream the starting codon) genes. (B) ChIP analysis of both non-specific lgG (mock) and CREB binding to the SYT2 and SYT4 promoters in NG and HG neurons stimulated with vehicle (NT), 20 mM potassium chloride (KCl) or $10 \mu \mathrm{M}$ forskolin (Fsk). Real Time analysis was performed in triplicate. Experiments were repeated six times using independent DNA samples (statistics by two-way ANOVA and Bonferroni post hoc). (C) Immunoblot analysis and bar graphs showing the expression of SYT4 in NG or HG neurons treated with vehicle, $\mathrm{KCl}$ or Fsk. The experiment was repeated five times (statistics by two-way ANOVA and Bonferroni post hoc). (D) Immunoblot analysis and bar graphs showing the expression of SYT4 in the hippocampus of CTR and STZ mice ( $n=6$ mice; statistics by unpaired Student's $t$-test). Data are expressed as mean \pm SEM. ${ }^{*} p<0.05 ;{ }^{* \star} p<0.01 ;{ }^{* \star} p<0.001 ;$ n.s. not significant. 
A

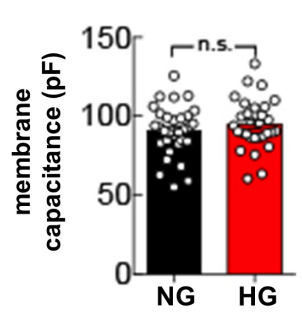

D

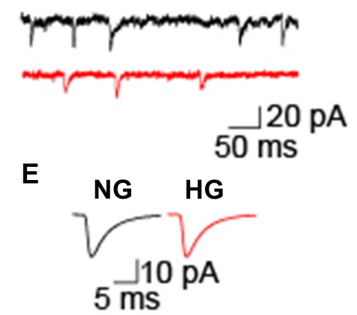

H

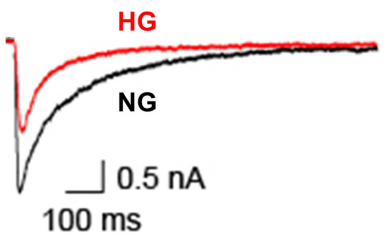

B

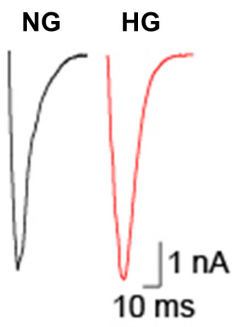

$\mathbf{F}$

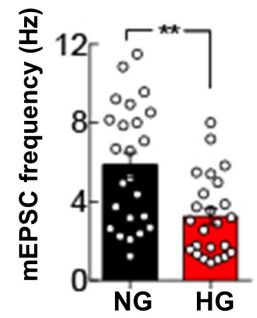

C

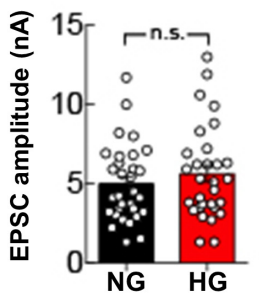

G

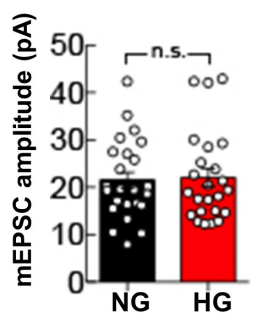

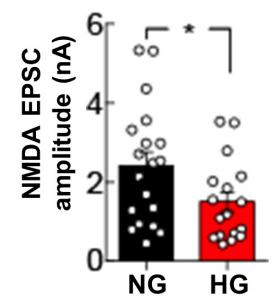

K

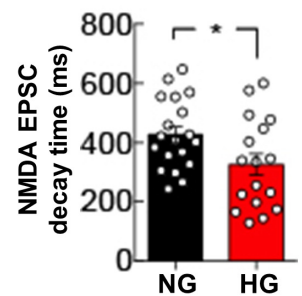

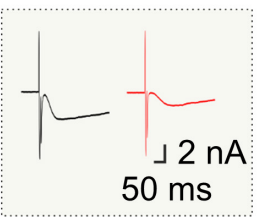

$\mathbf{L}$

FIGURE 4 | High glucose treatment impairs mEPSC frequency and NMDA receptor-mediated currents. (A) Quantification of membrane capacitance recorded in autaptic microcultures grown in NG $(n=31)$ or HG conditions $(n=30)$. (B) Representative traces of EPSC evoked by stimuli mimicking single action potentials recorded in NG- and HG-treated autaptic neurons. (C) Summary graphs of EPSC amplitudes recorded from autaptic neurons grown in either NG ( $n=31$ ) or HG $(n=31)$. (D) Example traces showing spontaneous mEPSCs from NG- and HG-treated autaptic neurons. (E) Representative mEPSC averaged traces. Summary graphs of mEPSC frequency ( $n=24$ per group) (F) and mEPSC amplitudes ( $n=24$ per group) (G). (H) Representative traces of NMDA receptor-mediated currents evoked by stimuli mimicking single action potentials and recorded in NG- and HG-treated autaptic neurons. (I) Inset: raw traces of H. Summary graphs of NMDA receptor-mediated currents amplitude (J) and decay time (K) from autaptic neurons grown in NG $(n=19)$ and in HG $(n=17)$. (L) Summary graphs of the AMPA:NMDA ratio recorded from autaptic neurons grown in either $\mathrm{NG}(n=15)$ or $\mathrm{HG}(n=14)$. Data are expressed as mean $\pm \mathrm{SEM}$. ${ }^{*} p<0.05$; ${ }^{\star \star} p<0.001$; $\mathrm{n} . \mathrm{s}$. not significant. Statistic by Mann-Whitney U-test, mEPSC amplitudes were analyzed with the Kolmogorov-Smirnov test.

with bath application of glutamate we stimulated the entire AMPA receptors pool expressed on cell membrane, instead of the synaptic pool only, without significantly affecting the
NMDA receptors that, at resting membrane potential, are mostly blocked by extracellular $\mathrm{Mg}^{2+}$. To test whether glucose dyshomeostasis affected NMDA receptors, we measured evoked 
NMDA receptor-mediated currents by using a $\mathrm{Mg}^{2+}$-free external solution and suppressing the AMPA receptor-mediated component of the EPSC with $10 \mu \mathrm{M}$ 2,3-dihydroxy-6-nitro-7sulfamoyl-benzo(F)quinoxaline-2,3-dione (NBQX).

Under NG conditions, hippocampal autapses depolarized with stimuli mimicking action potentials evoked robust NMDA receptor-mediated currents $(2.4 \pm 0.4 \mathrm{nA})$. Conversely, $\mathrm{HG}$ significantly reduced the NMDA receptor-mediated currents $(1.5 \pm 0.3 \mathrm{nA}, p=0.03$; Figures $4 \mathbf{H}-\mathbf{J})$. Interestingly, $\mathrm{HG}$ also significantly changed the decay time of NMDA receptormediated currents $(426.8 \pm 28.1 \mathrm{~ms}$, in NG condition and $326.2 \pm 38.0 \mathrm{~ms}$, in HG condition, $p=0.04$; Figures $4 \mathbf{H}, \mathbf{K}$ ). Finally, we measured the ratio between AMPA receptor-mediated and NMDA receptor-mediated EPSCs, which is a standard test to detect changes in synaptic strength (Kauer and Malenka, 2007). Autaptic hippocampal neurons grown in HG condition displayed a significant increase in the AMPA/NMDA ratio (3.9 \pm 0.5 , compared with $2.6 \pm 0.4$ seen in the NG autaptic hippocampal neurons; $p=0.0292$, Figure 4L). Collectively, our data demonstrate that glucose overload impairs glutamatergic synaptic transmission at both pre- and post-synaptic levels.

\section{DISCUSSION}

Epidemiological evidence indicated that diabetic patients are significantly more susceptible to develop cognitive impairment, and elevated blood glucose levels increase the risk of dementia in both diabetic and non-diabetic individuals (Cukierman-Yaffee, 2009; Crane et al., 2013). Several molecular mechanisms have been proposed to underlie the hyperglycaemia-related alterations of brain plasticity, including the depletion of stem cell niche, the development of brain insulin resistance, microvascular complications and neuroinflammation (Hsu and Kanoski, 2014; Fusco et al., 2016; Spinelli et al., 2019). However, how glucose overload affects synaptic transmission and plasticity remains still poorly understood. Here, we found that a well-established animal model of hyperglycaemia, i.e., the STZ-injected mice, exhibited memory deficits (Figure 1B) associated with molecular changes in the hippocampus including lower amounts of NMDA receptor subunits GluN1 and GluN2a (Figure 1C), reduced phosphorylation levels of memory-related transcription factor CREB (Figure 1C) and decreased expression of genes encoding for synaptic proteins regulating synaptic transmission and plasticity such as SYT2, SYT4 and BDNF (Figure 1D). CREB is a pivotal hub in the activity-driven neuronal gene expression (Benito et al., 2011) and its activity has been reported to be critically reduced in the context of aging and age-associated brain diseases (Zuccato et al., 2001; Cui et al., 2006; Caccamo et al., 2010). In the last years, we identified CREB as novel metabolic sensor in the brain, whose transcriptional activity was finely regulated by the nutrient availability (Fusco et al., 2012; Fusco and Pani, 2013). To deeply investigate the CREB-related molecular and functional changes due to the glucose overload on hippocampal neurons, we studied the effect of medium containing HG levels on both hippocampal primary neurons and autaptic hippocampal neurons. Exposure of neurons to $\mathrm{HG}$ simulated the molecular changes observed in the hippocampus of STZ mice, including the inhibition of CREB activity (Figure 2B). More importantly, HG impaired the CREB phosphorylation induced by drugs mimicking neuronal activity and abolished the upregulation of synaptotagmins 2 and 4 (Figure 2B,C). This sort of "negative priming" of activity-dependent CREB response might be mediated by the inhibition of CREB activators AMP-activated protein kinase and Sirtuin 1 in high glucose condition (Fusco et al., 2012; Peng et al., 2016). Interestingly, it has been demonstrated that SYTs, in addition to control the neurotransmitter release on presynaptic side, can also play a critical role in regulating the exocytosis of postsynaptic receptors at postsynaptic level (Wu et al., 2017). Accordingly, SYT4 mutant mice showed deficits of hippocampus-dependent learning and memory (Ferguson et al., 2000).

Our electrophysiological experiments performed in autaptic hippocampal neurons indicated that glucose excess impaired the spontaneous release of glutamate from presynaptic terminals whereas the evoked release and paired-pulse ratio were not affected (Figure 4). The decreased mEPSCs frequency we observed could be attributed to the downregulated expression of key proteins involved in synaptic vesicles fusion (Figure 2). However, other mechanisms might be also involved. First, glycaemia homeostasis imbalance has been reported to decrease intracellular $\mathrm{Ca}^{2+}$ levels (Chan and Greenberg, 1991). Another possible explanation of mEPSCs frequency alteration observed in HG-treated neurons is that the number of vesicles in presynaptic terminals and in the readily releasable pool of synaptic vesicles were different in NG- and HG-treated neurons. Furthermore, prolonged exposure to high levels of extracellular glucose may induce insulin resistance desensitizing insulin receptors. Specifically, it has been demonstrated that downregulation of insulin receptors signaling resulted in a significant reduction in the frequency of mEPSCs without affecting either the distribution of their amplitudes or the presynaptic release probability (Chiu et al., 2008; Lee et al., 2011).

To answer the fundamental question on how HG adversely impacts synapse function, we extended our analysis to the postsynaptic site by recording the NMDA receptor-mediated currents. We observed that HG differentially affected the evoked AMPA and NMDA receptor-mediated currents. Specifically, AMPA receptor-mediated currents were unaffected by $\mathrm{HG}$ treatment (Figures 4B,C). Conversely, we observed a significant reduction of NMDA receptor-mediated currents together with a reduction of the decay time in HG-treated neurons (Figure $4 \mathbf{H}-$ $\mathbf{K})$. These data, including the increased AMPA/NMDA ratio observed in HG neurons, suggest that glucose dyshomeostasis preferentially targets NMDA receptors, although our Western blotting analysis performed in the hippocampus of STZ mice revealed a significant reduction of GluA2 subunits (Figure 1C). Of note, the streptozotocin-induced type 1 diabetes model is characterized by more complex metabolic changes, including drastic decrease of insulin levels and alteration of leptin signalling, which may explain the differences between our in vivo and in vitro models (MacDougald et al., 1995). 
NMDA is a tetrameric receptor with two obligatory GluN1 subunits and two regulatory subunits, GluN2A and GluN2B (Yashiro and Philpot, 2008). The kinetics of NMDA receptor mediated currents reflect a different subunit composition of NMDA receptors which influences their $\mathrm{Ca}^{2+}$ permeability. Faster kinetics indicates lower $\mathrm{Ca}^{2+}$ influx through NMDA receptors (Yashiro and Philpot, 2008; Lee et al., 2010). In HG neurons, we found faster NMDA decay times suggesting lower $\mathrm{Ca}^{2+}$ influx (Figures $\mathbf{4 H}, \mathbf{J}$ ). Thus, we are proposing that glucose excess would influence the threshold for synaptic plasticity by affecting synaptic metaplasticity. Intriguingly, spontaneous glutamate release, instead of evoked release, adjusts functional and structural plasticity threshold at single synapses by local regulation of NMDA receptors (Lee et al., 2010). Our data support the idea that dietary regimen may influence brain plasticity, at least in part, by modifying CREB activity via altered glucose metabolism homeostasis (Mainardi et al., 2012). Of note, the beneficial effects of calorie restriction on synaptic plasticity and memory were abolished in mice lacking CREB in the forebrain (Fusco et al., 2012). However, glucose excess could also negatively impact on synaptic function by changing the intracytoplasmatic $\mathrm{Ca}^{2+}$ clearance (Nakashima et al., 1996), enhancing oxidative stress (Treviño et al., 2015) and impairing astrocyte energy metabolism (Li et al., 2018).

Here, we identified novel CRE regions on the regulatory sequences of SYT 2 and SYT4 genes, which may trigger the HG-dependent changes of synaptic function (Figure 3A). A fundamental question is whether SYTs also contribute to postsynaptic responses during neurotransmission. SYT4 deficiency has been demonstrated to modify the release of neurotrophic factor BDNF at postsynaptic level (Dean et al., 2009). BDNF has been recognized as strong modulator of multiple neuronal functions including synaptic plasticity, learning and memory (Minichiello, 2009; Fusco et al., 2019). Collectively, our data provide new insights into the glucoseresponsive CREB modulation of synaptic proteins regulating synaptic vesicle release. An intriguing hypothesis is that glucose availability influences the activity-dependent recruitment of CREB to the synaptotagmin promoters (Figure 3B) and the level of synaptic proteins controlling the vesicle release. The inhibition of spontaneous glutamate release together with the decrease of neurotrophin levels could contribute to synaptic function deficit observed in experimental models of diabetes. Specifically, the observed defects in mEPSC frequency may adversely affect the activity of NMDA receptors, which in turn regulate synaptic plasticity, learning and memory. Moreover, lower expression of synaptic proteins may elicit the decrease of both dendritic branching and spine density observed in experimental models of hyperglycaemia (Malone et al., 2008).

As mentioned above, hyperglicaemia and alteration of glucose homeostasis have been implicated in age-dependent cognitive decline and memory loss, although the molecular mechanisms are still elusive. Our findings reveal a novel molecular circuit that regulates synaptic transmission at pre- and post-synaptic levels involving CREB-dependent-downregulation of SYTs. A different model of insulin resistance-dependent hyperglycaemia, i.e., high fat diet (HFD)-fed mice, showed similar memory deficits and impairment of synaptic functions compared to STZ mice that were primarily attributed to aberrant protein palmitoylation (Yan et al., 2016; Spinelli et al., 2017). HFD also inhibits CREB phosphorylation in the hippocampus (Wu et al., 2018), as well as the expression of genes encoding SYT2 and SYT4 in mouse cerebral cortex (Yoon et al., 2019). However, despite sharing several functional and behavioral alterations, HFD and STZ models also differ for a number of intracellular molecular cascades relying on insulin resistance primarily occurring in the former. Future studies are needed to better understand the role of glucose-driven CREB transcriptional activity in agedependent memory loss and its potential impact on personalized medicine approaches.

\section{DATA AVAILABILITY STATEMENT}

The raw data supporting the conclusions of this article will be made available by the authors, without undue reservation.

\section{ETHICS STATEMENT}

The animal study was reviewed and approved by the Ethics Committee of Università Cattolica del Sacro Cuore and were fully compliant with Italian (Ministry of Health guidelines, Legislative Decree No. 116/1992) and European Union (Directive No. 86/609/EEC) legislations on animal research.

\section{AUTHOR CONTRIBUTIONS}

CR, SF, and CG conceived the study, supervised the work, and wrote the manuscript. CR performed the electrophysiological experiments. MS performed the metabolic analyses and western blotting experiments. FN performed the gene expression analysis. SF designed and performed the behavioral and ChIP experiments. All authors commented on the manuscript and approved its final version.

\section{FUNDING}

This work was supported by the Italian Ministry of Health (GR2018-12366381 to SF) and intramural grants from the Catholic University (Linea D.3.2 2017 to CG).

\section{SUPPLEMENTARY MATERIAL}

The Supplementary Material for this article can be found online at: https://www.frontiersin.org/articles/10.3389/fcell.2020.00810/ full\#supplementary-material 


\section{REFERENCES}

Altarejos, J. Y., and Montminy, M. (2011). CREB and the CRTC co-activators: sensors for hormonal and metabolic signals. Nat. Rev. Mol. Cell Biol. 12, 141-151. doi: 10.1038/nrm3072

Attar, A., Ripoli, C., Riccardi, E., Maiti, P., Puma, D. D. L., Liu, T., et al. (2012). Protection of primary neurons and mouse brain from Alzheimer's pathology by molecular tweezers. Brain 135(Pt 12), 3735-3748. doi: 10.1093/brain/aws289

Benito, E., Valor, L. M., Jimenez-Minchan, M., Huber, W., and Barco, A. (2011). cAMP response element-binding protein is a primary hub of activity-driven neuronal gene expression. J. Neurosci. 31, 18237-18250. doi: 10.1523/jneurosci. 4554-11.2011

Brose, N., Brunger, A., Cafiso, D., Chapman, E. R., Diao, J., Hughson, F. M., et al. (2019). Synaptic vesicle fusion: today and beyond. Nat. Struct. Mol. Biol. 26, 663-668.

Caccamo, A., Maldonado, M. A., Bokov, A. F., Majumder, S., and Oddo, S. (2010). CBP gene transfer increases BDNF levels and ameliorates learning and memory deficits in a mouse model of Alzheimer's disease. Proc. Natl. Acad. Sci. U.S.A. 107, 22687-22692. doi: 10.1073/pnas.1012851108

Chan, J., and Greenberg, D. A. (1991). Effects of glucose on calcium channels in neural cells. Neurosci. Lett. 121, 34-36. doi: 10.1016/0304-3940(91)90642-7

Chiu, S. L., Chen, C. M., and Cline, H. T. (2008). Insulin receptor signaling regulates synapse number, dendritic plasticity, and circuit function in vivo. Neuron 58, 708-719. doi: 10.1016/j.neuron.2008.04.014

Crane, P. K., Walker, R., and Larson, E. B. (2013). Glucose levels and risk of dementia. N. Engl. J. Med. 369, 1863-1864. doi: 10.1056/nejmc1311765

Cui, L., Jeong, H., Borovecki, F., Parkhurst, C. N., Tanese, N., and Krainc, D. (2006). Transcriptional repression of PGC-1alpha by mutant huntingtin leads to mitochondrial dysfunction and neurodegeneration. Cell 127, 59-69. doi: 10.1016/j.cell.2006.09.015

Cukierman-Yaffee, T. (2009). The relationship between dysglycemia and cognitive dysfunction. Curr. Opin. Invest. Drugs 10, 70-74.

Dean, C., Liu, H., Dunning, F. M., Chang, P. Y., Jackson, M. B., and Chapman, E. R. (2009). Synaptotagmin-IV modulates synaptic function and LTP by regulating BDNF release. Nat. Neurosci. 12, 767-776. doi: 10.1038/nn.2315

Deisseroth, K., Bito, H., and Tsien, R. W. (1996). Signaling from synapse to nucleus: postsynaptic CREB phosphorylation during multiple forms of hippocampal synaptic plasticity. Neuron 16, 89-101. doi: 10.1016/s0896-6273(00)80026-4

Duffy, C. M., Hofmeister, J. J., Nixon, J. P., and Butterick, T. A. (2019). High fat diet increases cognitive decline and neuroinflammation in a model of orexin loss. Neurobiol. Learn. Mem. 157, 41-47. doi: 10.1016/j.nlm.2018.11.008

Fattorini, G., Ripoli, C., Cocco, S., Spinelli, M., Mattera, A., Grassi, C., et al. (2019). Glutamate/GABA co-release selectively influences postsynaptic glutamate receptors in mouse cortical neurons. Neuropharmacology 161:107737. doi: 10. 1016/j.neuropharm.2019.107737

Ferguson, G. D., Anagnostaras, S. G., Silva, A. J., and Herschman, H. R. (2000). Deficits in memory and motor performance in synaptotagmin IV mutant mice. Proc. Natl. Acad. Sci. U.S.A. 97, 5598-5603. doi: 10.1073/pnas.100104597

Fernández-Chacón, R., Königstorfer, A., Gerber, S. H., García, J., Matos, M. F., Stevens, C. F., et al. (2001). Synaptotagmin I functions as a calcium regulator of release probability. Nature 410, 41-49. doi: 10.1038/35065004

Finkbeiner, S. (2000). CREB couples neurotrophin signals to survival messages. Neuron 25, 11-14. doi: 10.1016/s0896-6273(00)80866-1

Fusco, S., Leone, L., Barbati, S. A., Samengo, D., Piacentini, R., Maulucci, G., et al. (2016). A CREB-Sirt1-Hes1 circuitry mediates neural stem cell response to glucose availability. Cell Rep. 14, 1195-1205. doi: 10.1016/j.celrep.2015.12.092

Fusco, S., Maulucci, G., and Pani, G. (2012). Sirt1: def-eating senescence? Cell Cycle 11, 4135-4146. doi: 10.4161/cc.22074

Fusco, S., and Pani, G. (2013). Brain response to calorie restriction. Cell Mol. Life Sci. 70, 3157-3170. doi: 10.1007/s00018-012-1223-y

Fusco, S., Ripoli, C., Podda, M. V., Ranieri, S. C., Leone, L., Toietta, G., et al. (2012). A role for neuronal cAMP responsive-element binding (CREB)-1 in brain responses to calorie restriction. Proc. Natl. Acad. Sci. U.S.A. 109, 621-626. doi: 10.1073/pnas.1109237109

Fusco, S., Spinelli, M., Cocco, S., Ripoli, C., Mastrodonato, A., Natale, F., et al. (2019). Maternal insulin resistance multigenerationally impairs synaptic plasticity and memory via gametic mechanisms. Nat. Commun. 10:4799. doi: 10.1038/s41467-019-12793-3
Gispen, W. H., and Biessels, G. J. (2000). Cognition and synaptic plasticity in diabetes mellitus. Trends Neurosci. 23, 542-549. doi: 10.1016/s0166-2236(00) 01656-8

Hsu, T. M., and Kanoski, S. E. (2014). Blood-brain barrier disruption: mechanistic links between Western diet consumption and dementia. Front. Aging Neurosci. 6:88. doi: 10.3389/fnagi.2014.00088

Kauer, J. A., and Malenka, R. C. (2007). Synaptic plasticity and addiction. Nat. Rev. Neurosci. 8, 844-858. doi: 10.1038/nrn2234

Kullmann, S., Heni, M., Hallschmid, M., Fritsche, A., Preissl, H., and Haring, H. U. (2016). 'Brain insulin resistance at the crossroads of metabolic and cognitive disorders in humans. Physiol. Rev. 96, 1169-1209. doi: 10.1152/physrev.00032

Lee, C. C., Huang, C. C., and Hsu, K. S. (2011). Insulin promotes dendritic spine and synapse formation by the PI3K/Akt/mTOR and Racl signaling pathways. Neuropharmacology 61, 867-879. doi: 10.1016/j.neuropharm.2011.06.003

Lee, M. C., Yasuda, R., and Ehlers, M. D. (2010). Metaplasticity at single glutamatergic synapses. Neuron 66, 859-870. doi: 10.1016/j.neuron.2010. 05.015

Li, W., Roy Choudhury, G., Winters, A., Prah, J., Lin, W., Liu, R., et al. (2018). Hyperglycemia alters astrocyte metabolism and inhibits astrocyte proliferation. Aging Dis. 9, 674-684.

MacDougald, O. A., Hwang, C. S., Fan, H., and Lane, M. D. (1995). Regulated expression of the obese gene product (leptin) in white adipose tissue and 3T3L1 adipocytes. Proc. Natl. Acad. Sci. U.S.A. 92, 9034-9037. doi: 10.1073/pnas. 92.20.9034

Mainardi, M., Fusco, S., and Grassi, C. (2012). Modulation of hippocampal neural plasticity by glucose-related signaling. Neural Plast. 2015:657928. doi: 10.1155/ 2015/657928

Malone, J. I., Hanna, S., Saporta, S., Mervis, R. F., Park, C. R., Chong, L., et al. (2008). Hyperglycemia not hypoglycemia alters neuronal dendrites and impairs spatial memory. Pediatr. Diabetes 9, 531-539. doi: 10.1111/j.1399-5448.2008. 00431.x

Mantamadiotis, T., Lemberger, T., Bleckmann, S. C., Kern, H., Kretz, O., Martin Villalba, A., et al. (2002). Disruption of CREB function in brain leads to neurodegeneration. Nat. Genet. 31, 47-54. doi: 10.1038/ng882

Minichiello, L. (2009). TrkB signalling pathways in LTP and learning. Nat. Rev. Neurosci. 10, 850-860. doi: 10.1038/nrn2738

Nakashima, Y., Ishibashi, H., Harata, N., and Akaike, N. (1996). Effects of glucose deprivation on NMDA-induced current and intracellular Ca2+ in rat substantia nigra neurons. J. Neurophysiol. 75, 740-749. doi: 10.1152/jn.1996.75.2.740

Pascual-Leone, A., Amedi, A., Fregni, F., and Merabet, L. B. (2005). The plastic human brain cortex. Annu. Rev. Neurosci. 28, 377-401.

Peng, Y., Liu, J., Shi, L., Tang, Y., Gao, D., Long, J., et al. (2016). Mitochondrial dysfunction precedes depression of AMPK/AKT signaling in insulin resistance induced by high glucose in primary cortical neurons. J. Neurochem. 137, 701-713. doi: 10.1111/jnc.13563

Riccio, A., Ahn, S., Davenport, C. M., Blendy, J. A., and Ginty, D. D. (1999). Mediation by a CREB family transcription factor of NGF-dependent survival of sympathetic neurons. Science 286, 2358-2361. doi: 10.1126/science.286.5448. 2358

Ripoli, C., Cocco, S., Li Puma, D. D., Piacentini, R., Mastrodonato, A., Scala, F., et al. (2014). Intracellular accumulation of amyloid- $\beta(A \beta)$ protein plays a major role in $A \beta$-induced alterations of glutamatergic synaptic transmission and plasticity. J. Neurosci. 34, 12893-12903. doi: 10.1523/JNEUROSCI.120114.2014

Ripoli, C., Piacentini, R., Riccardi, E., Leone, L., Li Puma, D. D., Bitan, G., et al. (2013). Effects of different amyloid $\beta$-protein analogues on synaptic function. Neurobiol. Aging 34, 1032-1044. doi: 10.1016/j.neurobiolaging.2012.06.027

Spinelli, M., Fusco, S., and Grassi, C. (2019). Brain insulin resistance and hippocampal plasticity: mechanisms and biomarkers of cognitive decline. Front. Neurosci. 13:788. doi: 10.3389/fnins.2019.00788

Spinelli, M., Fusco, S., Mainardi, M., Scala, F., Natale, F., Lapenta, R., et al. (2017). Brain insulin resistance impairs hippocampal synaptic plasticity and memory by increasing GluA1 palmitoylation through FoxO3a. Nat. Commun. 8:2009. doi: 10.1038/s41467-017-02221-9

Südhof, T. C., and Rothman, J. E. (2009). Membrane fusion: grappling with SNARE and SM proteins. Science 323, 474-477. doi: 10.1126/science.1161748

Treviño, S., Aguilar-Alonso, P., Flores Hernandez, J. A., Brambila, E., Guevara, J., Flores, G., et al. (2015). A high calorie diet causes memory loss, metabolic 
syndrome and oxidative stress into hippocampus and temporal cortex of rats. Synapse 69, 421-433. doi: 10.1002/syn.21832

Wagatsuma, A., Azami, S., Sakura, M., Hatakeyama, D., Aonuma, H., and Ito, E. (2006). De novo synthesis of CREB in a presynaptic neuron is required for synaptic enhancement involved in memory consolidation. J. Neurosci. Res. 84, 954-960. doi: 10.1002/jnr.21012

West, A. E., and Greenberg, M. E. (2011). Neuronal activity-regulated gene transcription in synapse development and cognitive function. Cold Spring Harb. Perspect. Biol. 3:a005744. doi: 10.1101/cshperspect.a00 5744

Wu, D., Bacaj, T., Morishita, W., Goswami, D., Arendt, K. L., Xu, W., et al. (2017). Postsynaptic synaptotagmins mediate AMPA receptor exocytosis during LTP. Nature 544, 316-321. doi: 10.1038/nature21720

Wu, H., Liu, Q., Kalavagunta, P. K., Huang, Q., Lv, W., An, X., et al. (2018). Normal diet Vs High fat diet - a comparative study: behavioral and neuroimmunological changes in adolescent male mice. Metab. Brain Dis. 33, 177-190. doi: 10.1007/s11011-017-0140-z

Yan, S., Du, F., Wu, L., Zhang, Z., Zhong, C., Yu, Q., et al. (2016). F1F0 ATP synthase-Cyclophilin D interaction contributes to diabetes-induced synaptic dysfunction and cognitive decline. Diabetes $65,3482-3494$. doi: 10.2337/db160556

Yashiro, K., and Philpot, B. D. (2008). Regulation of NMDA receptor subunit expression and its implications for LTD, LTP, and metaplasticity. Neuropharmacology 55, 1081-1094. doi: 10.1016/j.neuropharm.2008. 07.046
Yoon, G., Cho, K. A., Song, J., and Kim, Y.-K. (2019). Transcriptomic analysis of high fat diet fed mouse brain cortex. Front. Genet. 10:83. doi: 10.3389/fgene. 2019.00083

Zhong, Y., Zhu, Y., He, T., Li, W., Li, Q., and Miao, Y. (2019). Brainderived neurotrophic factor inhibits hyperglycemia-induced apoptosis and downregulation of synaptic plasticity-related proteins in hippocampal neurons via the PI3K/Akt pathway. Int. J. Mol. Med. 43, 294-304. doi: 10.3892/ijmm. 2018.3933

Zito, K., and Svoboda, K. (2002). Activity-dependent synaptogenesis in the adult Mammalian cortex. Neuron. 35, 1015-1017. doi: 10.1016/s0896-6273(02) 00903-0

Zuccato, C., Ciammola, A., Rigamonti, D., Leavitt, B. R., Goffredo, D., Conti, L., et al. (2001). Loss of huntingtin-mediated BDNF gene transcription in Huntington's disease. Science 293, 493-498. doi: 10.1126/science.1059581

Conflict of Interest: The authors declare that the research was conducted in the absence of any commercial or financial relationships that could be construed as a potential conflict of interest.

Copyright $\odot 2020$ Ripoli, Spinelli, Natale, Fusco and Grassi. This is an open-access article distributed under the terms of the Creative Commons Attribution License (CC BY). The use, distribution or reproduction in other forums is permitted, provided the original author(s) and the copyright owner(s) are credited and that the original publication in this journal is cited, in accordance with accepted academic practice. No use, distribution or reproduction is permitted which does not comply with these terms. 